\title{
Additives for Superconformal Electroplating of Ag Thin Film for ULSIs
}

\author{
Eung Jin Ahn and Jae Jeong Kim*,z \\ Research Center for Energy Conversion and Storage, School of Chemical Engineering, Seoul National \\ University, Shillim-dong, Kwanak-gu, Seoul 151-742, South Korea
}

For Ag electroplating in a damascene structure, two additives were tried in the electrolyte composed of $\mathrm{KAg}(\mathrm{CN})_{2}$ and $\mathrm{KCN}$. One additive, thiourea, played a role as a suppressor and a brightener on a Ag seed layer. The other additive, benzotriazole, worked as an inhibitor on a $\mathrm{Cu}$ seed layer whereas it acted as an accelerator on the Ag seed layer. When these two additives were added to the electrolyte, the superconformal electroplating of Ag thin film for ultralarge scale integrateds (ULSIs) was accomplished successfully without defects in the damascene structure with a width of $400 \mathrm{~nm}$ and an aspect ratio was 4 .

(C) 2004 The Electrochemical Society. [DOI: 10.1149/1.1793811] All rights reserved.

Manuscript submitted January 26, 2004; revised manuscript received April 9, 2004. Available electronically September 7, 2004

As the speed of devices increases and the size of chips shrinks in ultralarge scale integrated circuits (ULSIs), Ag is thought to be the next material to $\mathrm{Cu}$ that can be an interconnection metal. This is because of its lowest bulk resistivity at room temperature as well as its higher resistance against oxidation and silicide formation compared with $\mathrm{Cu} .^{1-3}$

In Ag thin-film deposition, chemical vapor deposition (CVD) can result in precursor instability and high resistivity due to the carbon content. ${ }^{4,5}$ Based on the advantages of low process cost, simple facility, and process feasibility, Ag electroplating has a relatively higher potential in thin-film deposition. $\mathrm{Ag}$ electroplating has been investigated mainly by Moffat et al..$^{6-9}$ using $\mathrm{KSeCN}$ as an additive. ${ }^{8,9}$

This study proposes two additives for defect-free Ag thin film in electroplating processes. It focuses on achieving a superconformal electroplating of $\mathrm{Ag}$ thin film in trenches without voids and seams through the use of additives.

\section{Experimental}

Either a $\mathrm{Ag}$ or $\mathrm{Cu}$ seed layer $70 \mathrm{~nm}$ thick was physical vapordeposited (PVD) on TiN $(10 \mathrm{~nm}) / \mathrm{Ti}(15 \mathrm{~nm}) / \mathrm{Si}(100)$ substrates. As described in a later section, benzotriazole (BTA) has substratedependent properties and this is the reason for the employment of $\mathrm{Cu}$ seed. Besides, considering that the conventional seed layer thickness is very thin $(<70 \mathrm{~nm})$ compared to the main conductor line, $\mathrm{Cu}$ seed layer, although being used in $\mathrm{Ag}$ electroplating, does not negate the advantage of employment of $\mathrm{Ag}$ as an interconnection material. The TiN and Ti layers were formed by ionized metal plasma (IMP) PVD and metalorganic chemical vapor deposition (MOCVD), respectively. In the damascene structure, the aspect ratio was about four and the line width was $400 \mathrm{~nm}$.

An electronic grade $\mathrm{Ag}$ bar (1 $\mathrm{mm}$ in diameter, $3 \mathrm{~cm}$ in length) was used as an anode and a saturated calomel electrode (SCE) was used as reference electrode.

The electrolyte was composed of $0.92 \mathrm{M} \mathrm{KAg}(\mathrm{CN})_{2}, 1.1 \mathrm{M}$ $\mathrm{KCN}$, and deionized (DI) water. Weight concentrations of the two organic additives, thiourea (TU) and BTA, were varied from 0.1 to 5 $\mathrm{g} / \mathrm{L}$ and from 0.01 to $1 \mathrm{~g} / \mathrm{L}$, respectively. The Ag electroplating was carried out at $-800 \mathrm{mV} v \mathrm{~s}$. SCE, which was predetermined from the linear sweep voltammetry to set the plating in the charge-transfer control region and was controlled by an EG\&G scanning potentiostat (model 362) at room temperature. After electroplating, all samples were rinsed with DI water and dried in a continuous $\mathrm{N}_{2}$ stream.

Subsequent annealing process of plated $\mathrm{Ag}$ film was performed at $350^{\circ} \mathrm{C}$ for $30 \mathrm{~min}$ in a $\mathrm{N}_{2}$ atmosphere at $20 \mathrm{mTorr}$.

\footnotetext{
* Electrochemical Society Active Member.

${ }^{\mathrm{z}}$ E-mail: jjkimm@snu.ac.kr
}

The surface roughness, filling profile, and the deposition thickness were observed through atomic force microscopy and fieldemission scanning electron microscopy (FESEM). The Ag thin film was characterized using a four-point probe, Auger electron spectroscopy (AES), and X-ray diffraction spectroscopy (XRD).

\section{Results and Discussion}

TU and BTA showed different effects on Ag electroplating depending on the seed layer species. On the planar Ag seed layer, the addition of $5 \mathrm{~g} / \mathrm{L} \mathrm{TU}$ decreased the deposition rate by about $22 \%$ and also reduced the surface root-mean-square (rms) roughness by $56 \%$, showing both suppressing and brightening effects (Fig. 1a).
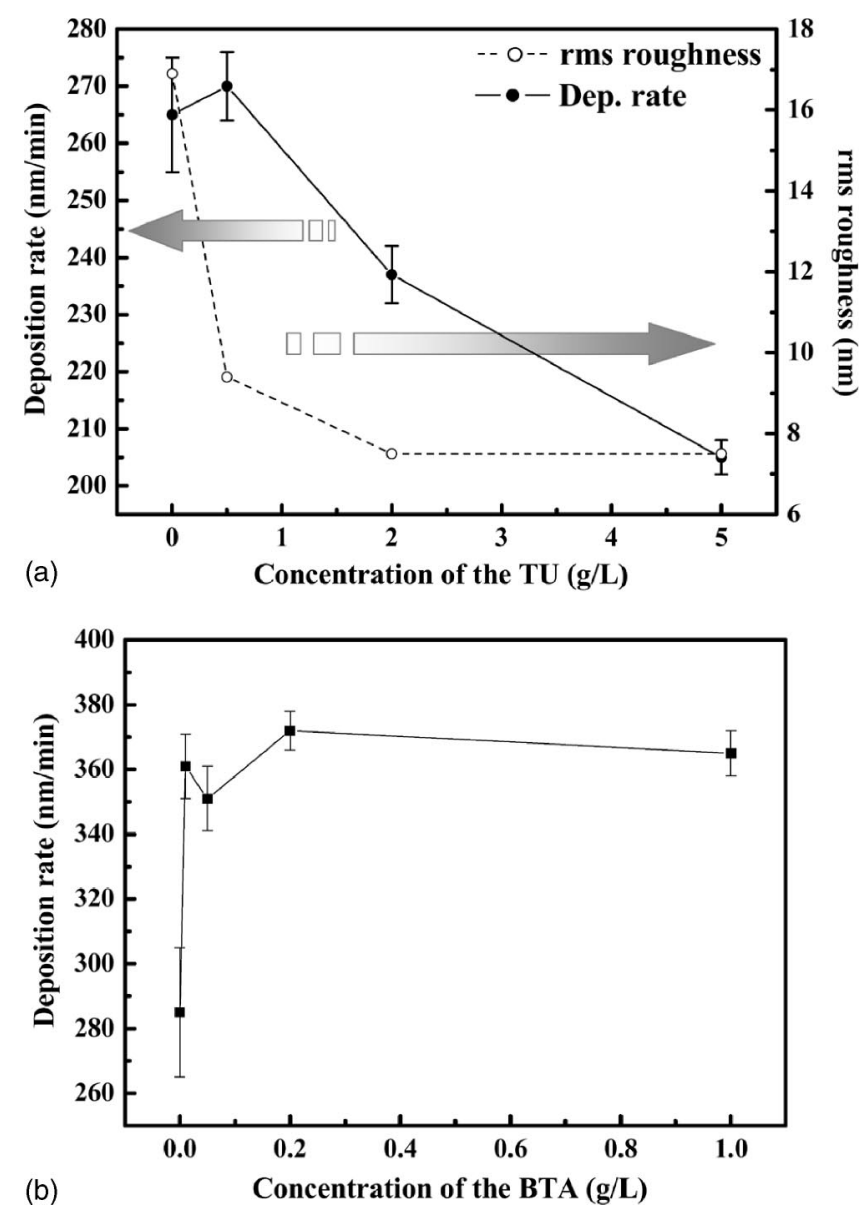

Figure 1. Effect of (a) TU and (b) BTA on the planar Ag seed layer. 

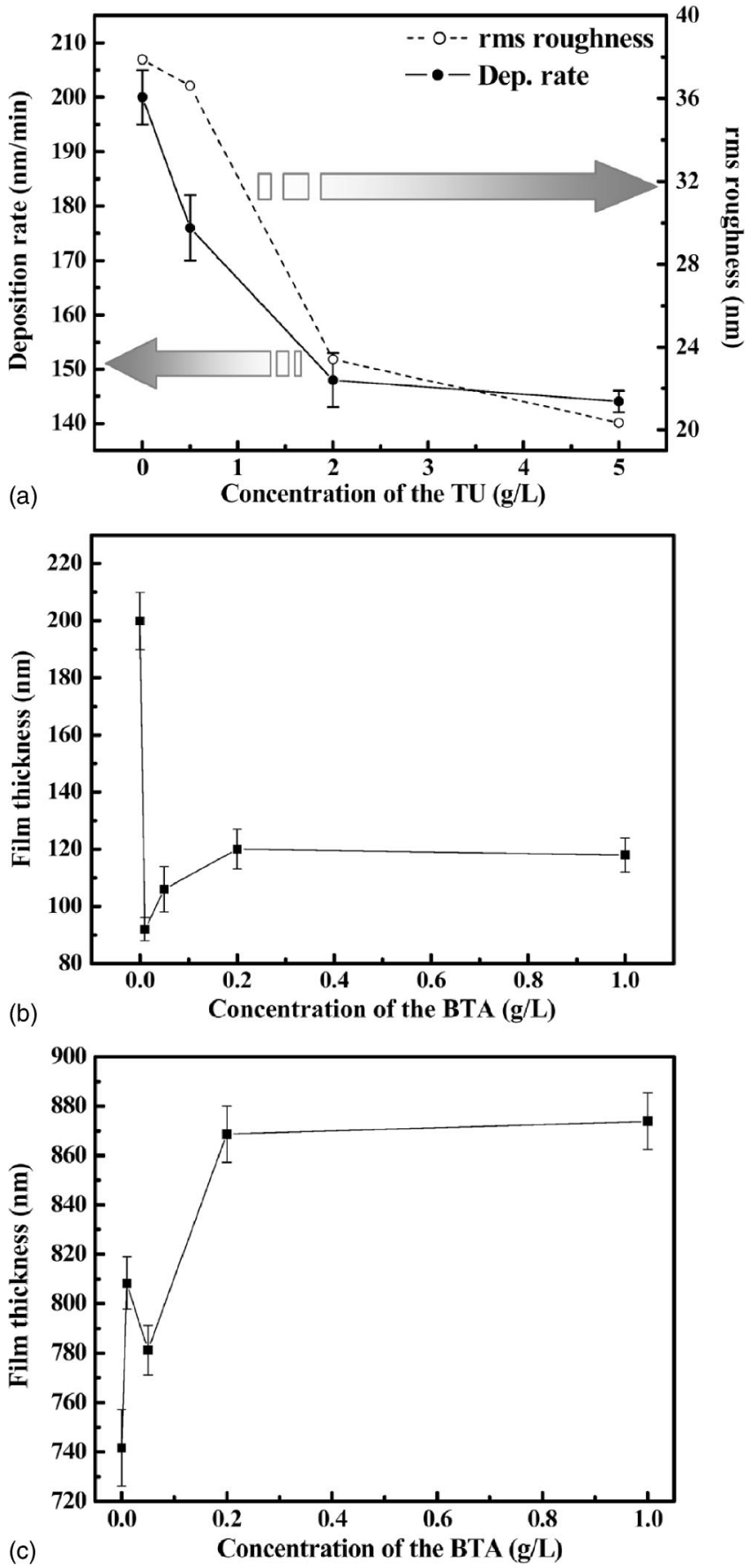

(c)

Figure 2. Effect of (a) TU, (b) BTA in the initial electroplating stage (60 s), and (c) BTA in the further electroplating time $(600 \mathrm{~s})$ on the planar $\mathrm{Cu}$ seed layer.

Figure $1 \mathrm{~b}$ exhibits that the acceleration effect of BTA, measuring from 0.01 to $1 \mathrm{~g} / \mathrm{L}$ increased the deposition rate by $30 \%$.

For the $\mathrm{Cu}$ seed layer, TU exhibited the same effects of suppression and brightening as shown in Fig. 2a. But BTA showed a different effect that depended on electroplating time: at the initial stage of $\mathrm{Ag}$ electroplating at $60 \mathrm{~s}$ BTA behaved like an inhibitor, something that was not observed in the planar Ag seed layer. When the plating time elapsed to $600 \mathrm{~s}$, an increase in the $\mathrm{Ag}$ film thickness was detected with an increase of BTA on the Ag seed layer. The inhibition effect at the state of plating was caused by strong adsorption of the BTA on the $\mathrm{Cu}$ seed layer (Fig. 2b). As reported in previous paper, ${ }^{10}$ BTA showed a strong adsorption on $\mathrm{Cu}$ surface, resulting in

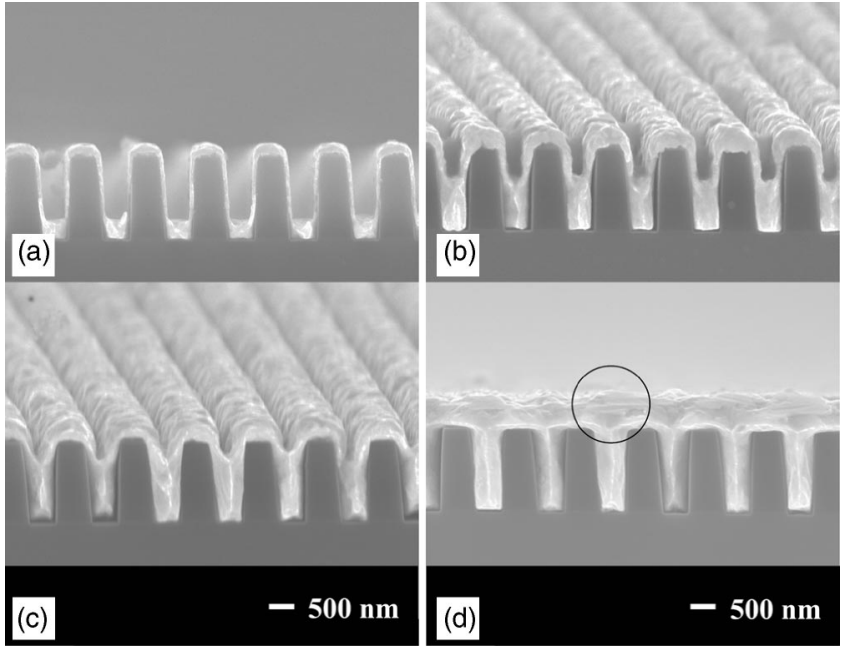

Figure 3. Time-dependence profiles of superconformal electroplating of $\mathrm{Ag}$ thin film for (a) 100, (b) 300, (c) 400, and (d) $600 \mathrm{~s}$ in the presence of TU and BTA. The circle indicates the bump.

excellent suppression behavior during $\mathrm{Cu}$ electrodeposition on the $\mathrm{Cu}$ seed layer. However, behavior of BTA on a Ag seed layer seems to be quite different, that is, opposite behavior. Therefore, at the early stage of $\mathrm{Ag}$ electroplating on a $\mathrm{Cu}$ seed layer, BTA shows a strong inhibition phenomena, as described previously. But once the $\mathrm{Ag}$ film is formed on the $\mathrm{Cu}$ seed layer, BTA shows an acceleration effect like the phenomena on the Ag seed layer. Therefore, the timedependent effect of BTA is restricted to electroplating on a $\mathrm{Cu}$ seed layer.

The best result for filling up the damascene structure was obtained when the combination of TU and BTA was applied to the damascene structure with the Ag seed layer. But even in this best case, the bottom-up fill characteristic was not accomplished. When TU and BTA were applied simultaneously to Ag electroplating in the same damascene structure with the copper seed, superconformal Ag electroplating was achieved successfully with bump formation through the optimized concentration of $5 \mathrm{~g} / \mathrm{L} \mathrm{TU}$ and $0.05 \mathrm{~g} / \mathrm{L}$ BTA. Figure 3 presents the time-dependent filling profiles and the bumps formed in Fig. 3d, proposed as proof of superconformal by West et al. ${ }^{11}$ as well as by Moffat et al. ${ }^{6-9}$ In the incipient stage of Ag electroplating on the $\mathrm{Cu}$ seed layer, BTA seemed to work as an inhibitor by adsorption on the $\mathrm{Cu}$ surface. As the $\mathrm{Ag}$ thin film was formed on the $\mathrm{Cu}$ seed, $\mathrm{TU}$ played a role as a suppressor and a brightener on the Ag film. BTA accelerated the bottom-up deposition of the Ag thin film as well as inhibited its formation during the initial electroplating time on the exterior of the trenches, resulting in

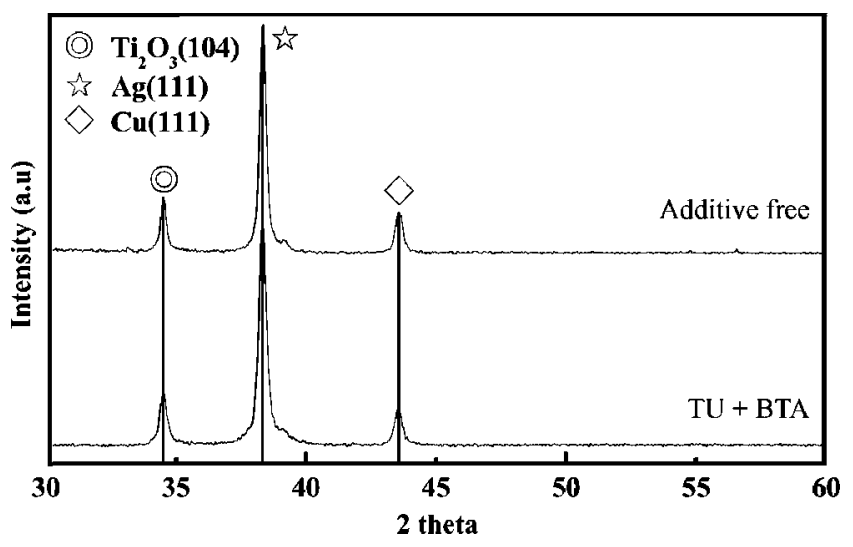

Figure 4. Crystallinity data of Ag thin films. 

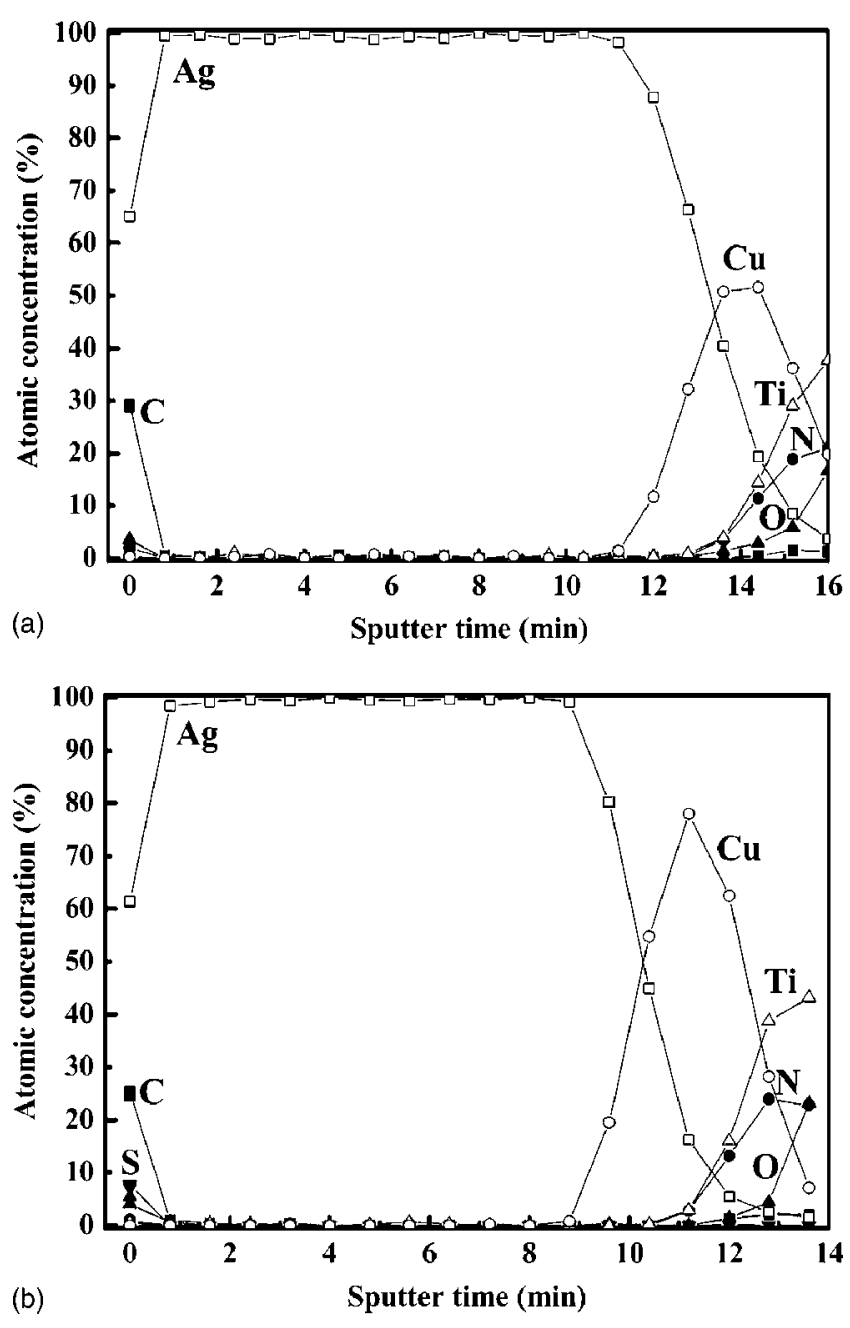

Figure 5. AES data of Ag thin films (a) additive free and (b) with TU and BTA addition.

the superconformal electroplating of $\mathrm{Ag}$ thin film in the damascene structure. From these results, the simple combination of suppressor and accelerator is not valid for $\mathrm{Ag}$ electroplating on a $\mathrm{Ag}$ seed layer. The differences between $\mathrm{Cu}$ and $\mathrm{Ag}$ can be classified as two factors; one is the evaluation of new additives and combination of them valid for Ag superfilling and the other is the employment of $\mathrm{Cu}$ seed to enhance the role of BTA.

In characterizing $\mathrm{Ag}$ thin films, its crystallinity did not change regardless of additives (Fig. 4). In Fig. 5, there was no impurity incorporated into the $\mathrm{Ag}$ thin film. In terms of resistivity, the as-

\begin{tabular}{|c|c|c|c|}
\hline \multirow{2}{*}{$\frac{\text { Wafers }}{\mathrm{a}}$} & \multicolumn{2}{|c|}{ Conditions } & \multirow{2}{*}{$\frac{\text { Resistivity }(\mu \Omega \mathrm{cm})}{1.82}$} \\
\hline & Additive free & As-plated & \\
\hline $\mathrm{b}$ & Additive free & Postannealed & 1.73 \\
\hline $\mathrm{c}$ & $\mathrm{TU}+\mathrm{BTA}$ & As-plated & 1.92 \\
\hline d & $\mathrm{TU}+\mathrm{BTA}$ & Postannealed & 1.70 \\
\hline
\end{tabular}

plated $\mathrm{Ag}$ thin films with additives showed a slightly higher value of $1.92 \mu \Omega \mathrm{cm}$. But the annealing process at $350^{\circ} \mathrm{C}$ for 30 min reduced resistivity of the electroplated $\mathrm{Ag}$ thin film down to $1.70 \mu \Omega \mathrm{cm}$ (Table I).

\section{Conclusion}

An experiment was done on electroplating method in cyanidebased electrolyte for Ag interconnection material. The filling characteristics of $\mathrm{Ag}$ thin film were considerably affected by the seed layer species and additives. With the addition of two organic additives, TU and BTA, one as a suppressor and the other as an accelerator, respectively, superconformal Ag thin film by electroplating was achieved in the damascene structure with an aspect ratio of 4 . No impurities were incorporated in the electroplated Ag thin film. Its resistivity was reduced to $1.70 \mu \Omega \mathrm{cm}$ from $1.92 \mu \Omega \mathrm{cm}$ through annealing.

\section{Acknowledgments}

This work was supported by the Korea Science and Engineering Foundation through the Research Center for Energy Conversion and Storage, LG Chemical Ltd., and by the Institute of Chemical Processes and Inter-university Semiconductor Research Center of Seoul National University.

Seoul National University assisted in meeting the publication costs of this article.

\section{References}

1. R. Manepalli, F. Stepniak, S. A. Bidstrup-Allen, and P. A. Kohl, IEEE Trans. Adv. Packag., 22, 4 (1999).

2. O. V. Zaplatynsky, Yu. M. Prots, P. S. Salamakha, L. O. Muratova, O. I. Bodak, J. Alloys Compd., 232, L1 (1996).

3. T. B. Massalski, J. L. Murray, L. H. Bennett, and H. Baker, Binary Alloy Phase Diagrams, p. 68, American Society for Metals, Metals Park, OH (1986).

4. C. Y. Hong, Y. C. Peng, L. J. Chen, W. Y. Hsieh, and Y. F. Hsieh, J. Vac. Sci. Technol. A, 17, 1911 (1999).

5. Z. Yuan, N. H. Dryden, J. J. Vittal, and R. J. Puddephatt, Chem. Mater, 7, 1696 (1995).

6. T. P. Moffat, B. Baker, D. Wheeler, J. E. Bonevich, M. Edelstein, D. R. Kelly, L. Gan, G. R. Stafford, P. J. Chen, W. F. Egelhoff, and D. Josell, J. Electrochem. Soc., 149, C423 (2002)

7. D. Josell, B. Baker, C. Witt, D. Wheeler, and T. P. Moffat, J. Electrochem. Soc., 149, C637 (2002).

8. B. C. Baker, M. Freeman, B. Melnick, D. Wheeler, D. Josell, and T. P. Moffat, $J$. Electrochem. Soc., 150, C61 (2003).

9. B. C. Baker, C. Witt, D. Wheeler, D. Josell, and T. P. Moffat, Electrochem. SolidState Lett., 6, C67 (2003).

10. J. J. Kim, S.-K. Kim, and J.-U. Bae, Thin Solid Films, 415, 101 (2002).

11. A. C. West, S. Mayer, and J. Reid, Electrochem. Solid-State Lett., 4, C50 (2001). 